\title{
Study of Serum Cyclophilin A Level in Patients with Acute Coronary Syndrome
}

\author{
ESRAA E. EMARA, M.Sc.*; MAALY M. MABROUK, M.D.*; TAIMOUR M. ABDALLAH, M.D.** and \\ THORYA E. BADAWY, M.D.* \\ The Departments of Clinical Pathology* and Cardiology**, Faculty of Medicine, Tanta University
}

\begin{abstract}
Background: Acute coronary syndrome (ACS) refers to a group of conditions due to diminished blood flow in the coronary arteries such that part of the heart muscle is incapable to act properly or dies.

Aim of Study: Is to evaluate the role of serum cyclophilin A level in acute coronary syndrome, its clinical significance in identifying patients with coronary artery disease and its correlation with the severity of the disease.

Methods: This study included 60 ACS cases, were subjected to full history taking. Clinical examination, Fasting blood glucose, Lipid profile (Total cholesterol, triglycerides, LDL and HDL), High sensitivity CRP, Troponin I level, CKMB level, Cyclophillin A. 20 apparently healthy age and sex matched subjects serving as a normal control group.

Results: Patients were divided into three groups unstable angina, NSTMI and STEMI. according to Cyclophilin A estimation: The mean values of serum Cyclophilin A level were significantly increased in unstable angina group, NSTMI group and STEMI group as compared to those in control group, there was also significant increase in NSTMI and STEMI as compared to those in group unstable angina.

Conclusion: From this study, it could be concluded that serum cyclophilin A levels Increased in patients with acute coronary syndrome and its associated with the progression of the disease suggesting its role in accelerating atheroscelerosis and may be a valuable marker for predicting the severity of ACS. So it is reasonable to assume that it could be a target for therapeutic treatment and its down regulation may be a new therapeutic strategy in ACS patients in near future.
\end{abstract}

Key Words: Acute coronary syndromes - Cyclophilin A Atherosclerosis

\section{Introduction}

ACUTE Coronary Syndrome (ACS) refers to a group of conditions due to diminished blood flow in the coronary arteries such that part of the heart muscle is incapable to act properly or dies [1]

Correspondence to: Dr. Esraa E. Emara,

The Department of Clinical Pathology, Faculty of Medicine, Tanta University
Chest pain is the most common symptom, often radiating to the left arm or angle of the jaw, pressure-like in character, and accompanied with nausea and sweating. Acute coronary syndrome usually occurs as a result of one of three problems, ST elevation myocardial infarction (STEMI), non ST elevation myocardial infarction (NSTEMI), or unstable angina (UA) [2]. These types are named according to the apparent show of the electrocardiogram as non-ST segment elevation myocardial infarction (NSTEMI) and ST segment elevation myocardial infarction (STEMI) [3]

Coronary atherosclerosis is the underlying condition for ACS, with very few exceptions as ACS is rarely caused by coronary dissection, arteritis, myocardial bridging, thromboembolism, or coronary vasospasm without obvious coronary artery disease [4]

Human Cyclophilins consist of 16 family members that are structurally distinct. Among them, the most abundant member is Cyclophilin A (CypA), which makes up to $0.1-0.6 \%$ of the total cytosolic proteins [5]

Cyclophilin A is an immunophilin secreted from human monocytes activated by high glucose, given its role as an inflammatory mediator of vascular tissue damage associated with inflammation and oxidative stress [6]. It is believed to have important roles in many biological conditions including protein folding, trafficking, and T-cell activation [7]

Previous studies showed that although CyPA is present intracellular; it can be secreted from cells in response to inflammatory stimuli such as hypoxia, infection, and oxidative stress [8] and suggesting its role in late stages of atherosclerosis and plaque rupture [9]. 


\section{Patients and Methods}

This retrospective study was carried out between March 2016 and October 2016 at Clinical Pathology Department, Tanta University.

Subjects: The present study included 80 subjects classified as follows: Group I: 20 apparently healthy volunteers (as a control group), Group UNSTABLE ANGINA: 20 patients with unstable angina, Group UNSTABLE ANGINAI: 20 patients with non ST segment elevation myocardial infarction, Group IV: 20 patients with ST segment elevation myocardial infarction.

A written informed consent was obtained from all students enrolled in the study after explaining the aim of the study and the procedures in which they will be involved. All subjects' related data were kept confidential. All subjects were given the right to withdraw at any step of the research. All these ethical procedures were reviewed, approved and monitored by the Faculty of Medicine Tanta University Research Ethics Committee.

\section{Exclusion criteria:}

Patients with infection, tumor, liver or kidney diseases were excluded from the study.

Methods: Patients were subjected to the following: Complete history with special emphasis age, sex, smokers, hypertension and diabetes mellitus also(ECG) and coronary angiography were done. Laboratory investigations including: Fasting blood glucose, lipid profile (Total cholesterol, triglycerides, LDL and HDL), high sensitivity CRP, troponin I level, CKMB level and Cyclophillin A. Cyclophilin A levels were measured using a commercially available enzyme-linked immune-sorbent assay (ELISA) kit.

\section{Statistical analysis of the data:}

Data were fed to the computer and analyzed using IBM SPSS software package Version 20.0. For quantitative data, the Shapiro-Wilk test for normality was performed. ROC-curve was used for assessment of sensitivity and specificity. Significance of the obtained results was judged at the $p$-value $<0.05$.

\section{Results}

In this work it was found that there was no significance difference among all studied groups as regard age and sex, however it was observed that the percentage of male patients with acute coronary syndrome was increased as compared to that of female patients in the same group. The result of this work revealed that the percentage of smokers, patients with diabetes mellitus and hypertension in the coronary artery disease group were significantly increased when compared to that of control group also the mean values of total serum cholesterol, triglyceride and LDL with concomitant a significant decrease of HDL in unstable angina and myocardial infarction groups as compared with the control group (Table 1).

The result of this work revealed a statistically significance increase in the mean values of serum hsCRP, CKMB in patients with unstable angina and myocardial infarction groups when compared to control group while Troponin I test was found to be positive in $100 \%$ of MI but negative in unstable angina (Table 2).

Table (1): Comparison between the studied groups.

\begin{tabular}{llllll}
\hline Parameter & $\begin{array}{l}\text { Group 1 } \\
(\mathrm{n}=30)\end{array}$ & $\begin{array}{l}\text { Group 2 } \\
(\mathrm{n}=20)\end{array}$ & $\begin{array}{l}\text { Group 3 } \\
(\mathrm{n}=20)\end{array}$ & Group 4 & $p$ \\
\hline Age in years & $53.7 \pm 5.5$ & $60.5 \pm 7.5$ & $58.9 \pm 8.1$ & $55.9 \pm 9.6$ & 0.067 \\
Sex (female/male) & $9 / 11$ & $7 / 13$ & $8 / 12$ & $6 / 14$ & 0.785 \\
Smoking (Smoker/non smoker) & $0 / 20$ & $3 / 17$ & $6 / 14$ & $14 / 6$ & $<0.001$ \\
$\begin{array}{l}\text { Diabetesmellitus } \\
\text { (diabetic/non diabetic) }\end{array}$ & $0 / 20$ & $11 / 9$ & $14 / 6$ & $14 / 6$ & $<0.001$ \\
Hypertention & & & & & \\
Total cholesterol (mg/dl) & $0 / 20$ & $9 / 11$ & $14 / 6$ & $16 / 4$ & $<0.001$ \\
Triglycerides (mg/dl) & $152.40 \pm 16.19$ & $190.65 \pm 23.35$ & $227.50 \pm 61.52$ & $261.40 \pm 36.91$ & $<0.001$ \\
LDL (mg/dl) & $87.65 \pm 8.94$ & $129.05 \pm 46.37$ & $172.30 \pm 64.47$ & $211.60 \pm 52.87$ & $<0.001$ \\
HDL (mg/dl) & $88.80 \pm 8.17$ & $118.10 \pm 23.35$ & $139.55 \pm 49.38$ & $150.75 \pm 40.14$ & $<0.001$ \\
\hline
\end{tabular}

Table (2): Comparison between the different studied groups according to HsCRP (mg/L).

\begin{tabular}{llllll}
\hline Parameter & $\begin{array}{c}\text { Group I } \\
(\mathrm{n}=20)\end{array}$ & $\begin{array}{c}\text { Group II } \\
(\mathrm{n}=20)\end{array}$ & $\begin{array}{c}\text { Group III } \\
(\mathrm{n}=20)\end{array}$ & $\begin{array}{c}\text { Group IV } \\
(\mathrm{n}=20)\end{array}$ & $p$ \\
\hline HsCRP (mg/L) & $0.61 \pm 0.21$ & $2.82 \pm 1.42$ & $4.77 \pm 1.82$ & $6.98 \pm 2.24$ & $<0.001$ \\
Troponin I (negative/positive) & $20 / 0$ & $20 / 0$ & $0 / 20$ & $0 / 20$ & \\
CKMB (U/L) & $5.20 \pm 1.85$ & $13.40 \pm 4.64$ & $97.40 \pm 36.80$ & $135.90 \pm 55.05$ & \\
\hline
\end{tabular}


As regard the result of cyclophilin A, the mean values of serum Cyclophilin A levels were significantly increased in ACS patient groups as compared to those in control group with more significant increase in MI groups (NSTEMI and STEMI) (Table 3) and (Fig. 1).

The present study also demonstrates that classical risk factors as smoking and hypertension, and all laboratory parameter levels, including LDL, triglycerides, total cholesterol, troponin I, CKMB and Hs CRP were in positive correlation with Cyclophilin A except for HDL showed negative correlation with Cyclophilin A (Tables 4,5).
In this work a linear regression analysis was significant for serum cyclophilin A and serum HsCRP while it was not significant for LDL gative correlation with Cyclophilin A (Table 6).

On the basis of the present findings ROC curve analysis in discriminating acute coronary syndrome patients showed that Cyclophilin A at a cut off level $>8.9 \mathrm{ng} / \mathrm{ml}$ had a diagnostic sensitivity of $81.67 \%$, specificity of $100 \%$, positive predictive values of $100 \%$ and negative predictive values of $64.5 \%$ with an area under the curve (AUC) of 0.893 (Tables 7,8) (Figs. 2,3).

Table (3): Comparison between the different studied groups according to cyclophilin A (ng/ml).

\begin{tabular}{llllll}
\hline Parameter & $\begin{array}{c}\text { Group I } \\
(\mathrm{n}=20)\end{array}$ & $\begin{array}{c}\text { Group II } \\
(\mathrm{n}=20)\end{array}$ & $\begin{array}{c}\text { Group III } \\
(\mathrm{n}=20)\end{array}$ & $\begin{array}{c}\text { Group IV } \\
(\mathrm{n}=20)\end{array}$ & $p$ \\
\hline Cyclophilin A $(\mathrm{ng} / \mathrm{ml}):$ & & & & \\
$\quad$ Range & $3.40-8.90$ & $3.37-25.41$ & $6.24-46.60$ & $11.96-53.40$ & $<0.001^{*}$ \\
$\quad$ Mean \pm SD. & $7.22 \pm 1.26$ & $10.31 \pm 4.39$ & $21.07 \pm 12.32$ & $25.54 \pm 15.14$ & \\
$p_{1}$ & & $0.001^{*}$ & $<0.001^{*}$ & $<0.001^{*}$ \\
Sig. bet. Grps & \multicolumn{3}{c}{$p 2=0.006^{*}, p_{3}<0.001^{*}, p 4=0.685$} \\
\hline
\end{tabular}

Table (4): Comparison between cyclophilin A in different risk factors of all patients groups.

\begin{tabular}{|c|c|c|c|c|c|c|c|}
\hline \multirow{2}{*}{ Risk factors } & \multirow{2}{*}{$\mathrm{N}$} & \multicolumn{2}{|c|}{ Cyclophilin A (ng/ml) } & \multirow{2}{*}{$p$} & \multirow{2}{*}{ Parameters } & \multicolumn{2}{|c|}{ Cyclophilin A } \\
\hline & & Min. - Max. & Mean \pm SD. & & & $r_{\mathrm{S}}$ & $p$ \\
\hline \multirow{3}{*}{$\begin{array}{l}\text { Smoking: } \\
\text { Smoker } \\
\text { Non smoker }\end{array}$} & & & & \multirow{3}{*}{$0.001 *$} & Fasting blood sugar & $0.436^{*}$ & $0.001 *$ \\
\hline & 23 & $4.96-53.08$ & $20.67 \pm 13.36$ & & Total cholesterol & $0.713 *$ & $<0.001 *$ \\
\hline & 37 & $3.37-51.21$ & $17.54 \pm 12.58$ & & Triglycerides & $0.717 *$ & $<0.001 *$ \\
\hline \multirow{4}{*}{$\begin{array}{l}\text { Diabetes } \\
\text { mellitus: } \\
\text { Diabetic } \\
\text { Non diabetic }\end{array}$} & & & & \multirow{4}{*}{$<0.001 *$} & LDL & $0.608 *$ & $<0.001 *$ \\
\hline & 39 & $7.10-53.08$ & $23.12 \pm 13.78$ & & HDL & $-0.657 *$ & $<0.001 *$ \\
\hline & 21 & $3.37-19.20$ & $10.61 \pm 4.56$ & & hsCRP & $0.693^{*}$ & $<0.001 *$ \\
\hline & & & & & CKMB & $0.762 *$ & $<0.001 *$ \\
\hline Hypertension: & & & & \multirow{2}{*}{$<0.001 *$} & Angiography & $0.774 *$ & $<0.001 *$ \\
\hline $\begin{array}{l}\text { Hypertension } \\
\text { Non } \\
\text { hypertension }\end{array}$ & $\begin{array}{l}39 \\
21\end{array}$ & $\begin{array}{l}1.10-53.08 \\
3.37-28.17\end{array}$ & $\begin{array}{l}23.40 \pm 13.33 \\
10.09 \pm 5.45\end{array}$ & & $\begin{array}{l}\text { (number of stenotic } \\
\text { coronary arteries) }\end{array}$ & & \\
\hline
\end{tabular}

Table (6): Linear regression for LDL (mg/dl), Cyclophilin A (ng/ml) and HsCRP (mg/l).

\begin{tabular}{lcccccc}
\hline Parameters & \multirow{2}{*}{$\mathrm{b}$} & \multirow{2}{*}{ S.E } & Sig. & \multirow{2}{*}{ OR } & \multicolumn{2}{c}{ 95\% C.I } \\
\cline { 6 - 8 } & & & & & Lower & Upper \\
\hline LDL (mg/dl) & 0.035 & 0.019 & 0.063 & 1.035 & 0.998 & 1.074 \\
Cyclophilin A (ng/ml) & 0.416 & 0.173 & $0.003^{*}$ & $1.515^{*}$ & 1.079 & 2.129 \\
HsCRP (mg/L) & 5.889 & 1.998 & $0.016^{*}$ & $361.129^{*}$ & 7.197 & 18119.55 \\
\hline
\end{tabular}

Table (7): Agreement (sensitivity, specificity) for Cyclophilin A ( $\mathrm{ng} / \mathrm{ml})$ to diagnose acute coronary syndrome patients.

\begin{tabular}{lccccc}
\hline Parameter & $\begin{array}{r}\text { Cut } \\
\text { off }\end{array}$ & Sensitivity Specificity & \multicolumn{2}{c}{ PPV NPV } \\
\hline $\begin{array}{l}\text { Cyclophilin A } \\
\text { (ng/ml) }\end{array}$ & $>8.9$ & 81.67 & 100.0 & 100.0 & 64.5 \\
\hline
\end{tabular}

Table (8): Agreement (sensitivity, specificity) to diagnose myocardial infarction from unstable angina.

\begin{tabular}{|c|c|c|c|c|}
\hline Parameter & $\begin{array}{l}\text { Cut } \\
\text { off }\end{array}$ & Sensitivity & Specificity & PPV NPV \\
\hline $\begin{array}{l}\text { Cyclophilin A } \\
\text { (ng/ml) }\end{array}$ & $>13.25$ & 77.5 & 95.0 & 96.9 \\
\hline
\end{tabular}




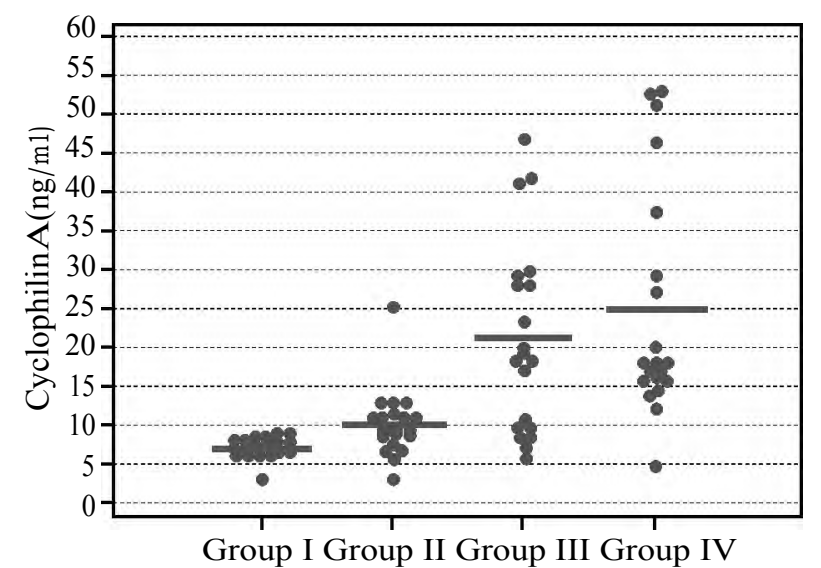

Fig. (1): Comparison between the different studied groups according to cyclophilin A level (ng/ml).

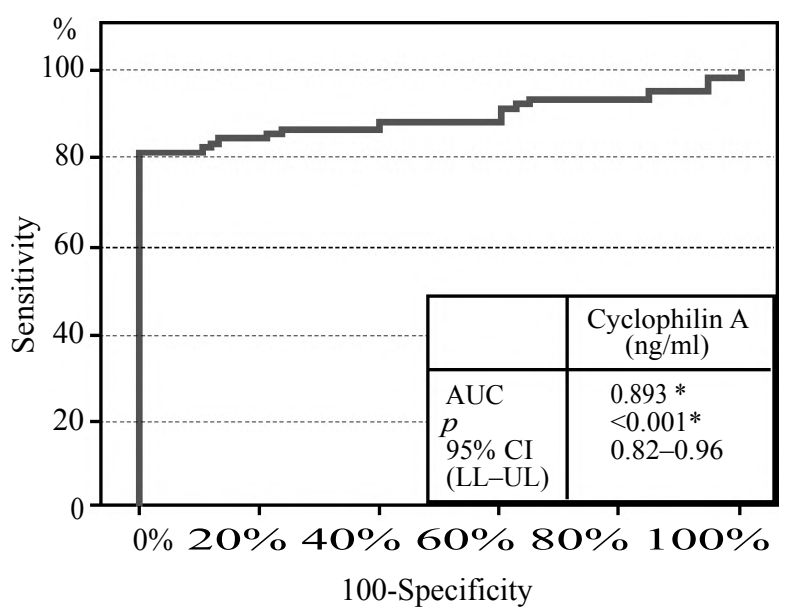

Fig. (2): ROC curve for Cyclophilin A ( $\mathrm{ng} / \mathrm{ml})$ to diagnose acute coronary syndrome patients.

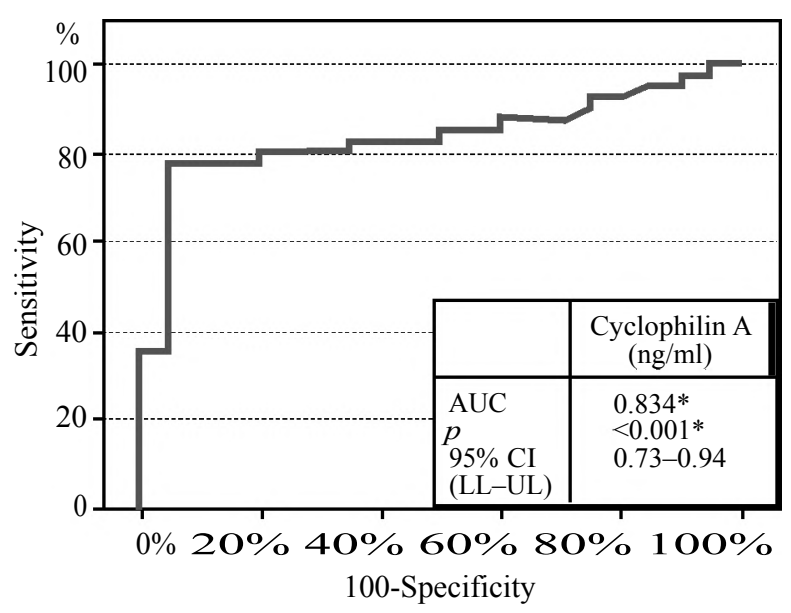

Fig. (3): ROC curve for Cyclophilin A ( $\mathrm{ng} / \mathrm{ml})$ to diagnose myocardial infarction from unstable angina.

\section{Discussion}

Atherosclerotic vascular disease, particularly coronary heart diseases are major causes of human morbidity and mortality in both industrialized and developing countries [10].
Coronary plaque disruption, with consequent platelet aggregation and thrombosis is the most important mechanism by which atherosclerosis lead to ACS of unstable angina, acute myocardial infarction and to some extent sudden cardiac death [11]

Acute coronary syndrome (ACS) refers to any group of clinical symptoms compatible with acute myocardial ischemia and covers the spectrum of clinical conditions ranging from unstable angina (UA) to non ST elevation myocardial infarction (NSTEMI) to ST elevation myocardial infarction (STEMI) [12]

Biochemical markers of myocardial injury are considered the gold standard for diagnosis of AMI and are particularly important in the non diagnostic ECG patients, the isoenzyme CKMB was reported the benchmark for comparison with other markers

It has been reported by Ramachandran et al., that Cyclophilin A shown to elicit inflammatory responses and thus contribute to recruitment of circulating blood cells during inflammatory response. Given that cyclophilin A is a potent chemotactic agent for immune cells, particularly monocytes; it is plausible that this immunophilin plays an important role in accelerating atherosclerosis

Seizer et al., reported that both extra- and intracellular CyPA significantly contribute to cardiovascular inflammation, myocardial ischaemia and reperfusion injury, and myocardial remodelling processes [15].

Jin et al., and Satoh et al., also reported that cyclophilin A is highly expressed at sites of unstable atherosclerotic plaques, especially those associated with macrophages and foam cells $[\mathbf{1 5 , 1 6}]$.

So the aim of the present study was to evaluate the role of serum cyclophilin A level in patients with acute coronary syndrome and to investigate the relationship between its serum level and the severity of the disease.

In this work it was found that there was no significance difference among all studied groups as regard age and sex, however it was observed that the percentage of male patients with acute coronary syndrome was increased as compared to that of female patients in the same group.

This was in agreement with Rossouw et al., who reported that men are more likely to develop coronary artery disease, stroke and other cardio- 
vascular manifestation of atherosclerosis. This is due to the protective effect of female hormones (estrogens) so that heart disease risk for women rises dramatically after menopause [18].

This comes with the fact that cardiovascular diseases are common in males than females. Cardiovascular diseases develops 7 to 10 years later in women than in men and are still the major cause of death in women over the age of 65 years. This risk of heart disease in women is often underestimated due to the misperception that females are protected against cardiovascular diseases [19]

Also Michelle reported that the incidence of coronary artery disease increases with age, men older than 45 and women older than 55 (or younger if they have premature menopause) are at greater risk of heart disease [20]

The result of this work revealed that the percentage of smoking was higher among cases of unstable angina and MI as compared to that of control group.

This agrees with Fusegama et al., who reported that the incidence of cardiovascular disease is increased six fold in women and three fold in men who smoke at least 20 cigarettes per day when compared to subjects who never smoked and the components of cigarette smoke are known to have a variety of thrombogenic effects [21].

In this study, it was found that the percentages of patients with diabetes mellitus with coronary artery disease group were significantly increased when compared to that of control group. This indicated that hyperglycemia is an important risk factor for atherosclerosis and have a role in development of CAD. This is in agreement with Boyle who demonstrated that hyperglycemia is one of the risk factors for atherosclerotic coronary artery disease [22] . Another study by Stephen et al., reported that diabetes is accompanied by more extensive atherosclerosis and inadequate compensatory remodeling [23]

In this work it was found that the percentages of patients with hypertension in the coronary artery disease group were significantly increased when compared to that in control group. This was in agreement with Foley et al., who reported that the hypertension is an important risk for development of cardiovascular disease which may play a role in atherogenesis process [24].

Data of the present study demonstrated a statistically significance increase in the mean values of total serum cholesterol, triglyceride and LDL with concomitant a significant decrease of HDL in unstable angina and myocardial infarction groups as compared with the control group.

Assmann et al., reported that epidemiologic studies have indicated that hyperlipidemia and low levels HDL are important risk factors for coronary heart diseases [25]. Gordon et al., also proved that the incidence of coronary heart disease was generally highest in those with a low HDL and lowest in those with high HDL [26].

Deng et al., described significantly raised value for atherogenic lipid as cholesterol and LDL in patients with coronary heart disease [27]. The significant relationship between the lipid profile and CAD was also detected by Ryoko et al., using invasive coronary angiography [28]

The result of this work revealed a statistically significance increase in the mean values of serum hsCRP in patients with unstable angina and myocardial infarction groups when compared to control group.

Ridker et al., show that serum hsCRP concentration in ACS patients was higher than in controls [29]. Inflammation plays a pivotal role in all stages of atherosclerosis, CRP which is the indicator for inflammatory reactions, has been reported to be a risk cardiac biomarker for ACS. Elevated serum concentrations of CRP are associated with poor prognosis in patients with cardiovascular diseases and predict possible further coronary events in population studies [30-32]

Troponin I test in this study was found to be positive in $100 \%$ of MI but negative in unstable angina, while CKMB was significant increased in both unstable angina and myocardial infarction compared to control group.

The significance of measuring cardiac troponins has been reported by Braunwald et al., as cardiac troponins typically are measured at emergency department admission and repeated in six to 12 hours [33]. Patients with a normal CK-MB level but elevated troponin levels are considered to have sustained minor myocardial damage or microinfarction, whereas patients with elevations of both CK-MB and troponins are considered to have had acute myocardial infarction. The cardiac troponins may remain elevated up to two weeks after symptom onset, which makes them useful as late markers of recent acute myocardial infarction, while CKMB typically is detectable in the serum four to six 
hours after the onset of ischemia, peaks in 12 to 24 hours, and normalizes in two to three days [34]

As regard the result of cyclophilin $\mathrm{A}$, the mean values of serum Cyclophilin A levels were significantly increased in ACS patient groups as compared to those in control group with more significant increase in MI groups (NSTEMI and STEMI).

According to Satoh et al., the increase in vascular oxidative stress requires CyPA which thereby sensitizes endothelial cells (ECs) to apoptosis. In addition, CyPA secretion is regulated by Rhokinase activation, which is important for vascular smooth muscle cells contraction and atherosclerosis. Consistently, serum levels of CyPA were significantly increased in patients with CAD [35].

Cyclophilin A is part of various intracellular functions, such as intracellular signaling, protein trafficking, and regulating activity of other proteins [36]. Cyclophilin A, is also well recognized as a secreted growth factor that is induced by oxidative stress [37]. Functioning as a mediator of tissue damage associated with inflammation and oxidative stress [36]. Thus the secretory nature of this protein and its presence in serum of patients with CAD underlines its potential as a marker of the disease.

Nigro et al., showed five mechanisms by which Cyp A promotes atherosclerosis First: CypA stimulates low density lipoprotein (LDL) uptake in the vessel wall by regulating the expression of scavenger receptors. Second: CypA increases endothelial cells activation and inflammation by increasing vascular cell adhesion molecule 1(VCAM-1) expression. Third: CypA decreases endothelial nitric oxide synthase (Enos) expression through Kruppellike factor 2 (KLF2) transcriptional repression in endothelial cells. Forth: CypA is a key determinant for tumor necrosis alpha (TNF-a) induced epithelial cell apoptosis. Fifth:CypA stimulates recruitment of inflammatory cells derived from BM to the aortic wall later phases by affecting plaque rupture and thrombosis [38].

Interestingly in this study the number of stenotic coronary arteries was in positive correlation with Cyclophilin A level which came in consistent with Satoh et al., who reported that Plasma CyPA levels were significantly higher in patients with significant coronary stenosis compared to those without it. A positive correlation was noted between plasma CyPA levels and significant coronary stenosis. The average number of stenotic coronary arteries and the need for coronary intervention were significantly increased in the quartiles of higher CyPA levels [39].
Satoh et al., also detected that the plasma CyPA level significantly correlated with the presence of $\mathrm{CAD}$ and plasma levels of CyPA increased according to the number of atherosclerotic risk factors that all of which induce oxidative stress. Furthermore, plasma levels of CyPA significantly reduced after medical treatment of risk factors. Finally, CyPA was strongly expressed in coronary atherosclerotic plaque in patients with myocardial infarction [39].

The present study also demonstrates that classical risk factors as smoking and hypertension, and all laboratory parameter levels, including LDL, triglycerides, total cholesterol, troponin I, CKMB and Hs CRP were in positive correlation with Cyclophilin A except for HDL showed negative correlation with Cyclophilin A.

In agreement with the present results Satoh et al., observed a positive correlation between the concentration of hsCRP and cyclophilin A in patient with ACS and CypA is better CRP to predict ACS

In addition Satoh et al., found that age; diabetes and HsCRP correlate with plasma cyclophilin A levels in their patients with stenotic coronary arteries [39].

Moreover, Ramachandran., verified the presence of Cyclophilin A (CypA) in monocytes of patients with type 2 diabetes mellitus and he concluded that CypA is a secretory factor released by monocytes in response to oxidative stress induced by high glucose. So, CyPA secreted by monocytes could have important effects on enhancing monocyte adhesion to endothelial cells and thus in the pathogenesis of atherosclerosis in type 2 diabetes

Therefore, it is logical to propose that agents which prevent CyPA binding to its receptors may have therapeutic potential. By blocking this vicious cycle that augments ROS production through CyPA autocrine/paracrine signaling pathway [42]

Importantly, CyPA is highly expressed at sites with unstable atherosclerotic plaques, especially those associated with macrophages and foam cells [40]. Based on the role of extracellular CyPA in MMP activation, it is reasonable to assume that agents that prevent CyPA receptor binding and reduce circulating CyPA may have therapeutic potential for inhibiting atherosclerotic plaque rupture. 
Yan et al., reported that secreted cyclophilin A is aproinflammatory cytokine which activates cardiovascular cells involved in different aspects of the disease process [43]

Also Seizer et al., reported that CypA seems to be a suitable target for prohibiting or treating inflammatory cardiovascular processes [44]

Therefore inhibition of CypA secretion and/or its binding to target receptor will be promising therapy for prevention and treatment in cardiovascular disease. So CypA may be obtained as novel therapeutic tool for controlling cardiovascular diseases in the near future. This warrants further investigation of the role of CyPA to identify potential CyPA-related therapeutic targets, although further basic and clinical studies are needed to identify CyPA-related therapeutic targets.

In this work a linear regression analysis was significant for serum cyclophilin A and serum HsCRP while it was not significant for LDL while Yan et al., showed that a linear regression analysis displayed that CyPA was better than CRP to predict ACS [43] .

Therefore CypA may obtained as a novel biomarker for oxidative stress in CAD and in near future as a therapeutic tool for controlling cardiovascular diseases.

\section{Conclusion:}

The significance of increasing Serum cyclophilin levels and its association with severity of the disease in patients with acute coronary syndrome suggesting the role of this protein in accelerating atheroscelerosis in ACS considering the evidence that Cyclophilin A is an inflammatory mediator in atherogenesis.

It may be considered as biomarker for ACS and it is reasonable to assume that it could be a target for therapeutic treatment in near future.

\section{Recommendations:}

Further studies on larger number of patients should be done for more comprehensive statistical analysis and better conclusions.

Further studies are required to evaluate role of cyclophilin A in other cardiac diseases rather than acute coronary syndrome.

Follow-up study is needed after ST elevated myocardial infarction to evaluate a CypA prognostic role for patient outcome.

\section{References}

1- AMSTERDAM E.A., WENGER N.K., BRINDIS R.G., CASEY D.E., GANIATS T.G., et al.: AHA/ACC Guideline for the Management of Patients With Non-ST-Elevation Acute Coronary Syndromes: A Report of the American College of Cardiology/American Heart Association Task Force on Practice Guidelines". Circulation, 130 (25): e344-e426, 2014.

2- TORRES M. and MOAYEDI S.: "Evaluation of the acutely dyspneic elderly patient". Clin. Geriatr. Med., 23 (2): 307-25, 2007.

3- GRECH E.D. and RAMSDALE D.R.: "Acute coronary syndrome: Unstable angina and non-ST segment elevation myocardial infarction". BMJ, 326 (7401): 1259-61, 2003.

4- GOODACRE S., LOCKER T., MORRIS F. and CAMPBELL S.: How useful are clinical features in the diagnosis of acute, undifferentiated chest pain. Acad. Emerg. Med., 9: 203-8, 2002.

5- DORNAN J., TAYLOR P. and WALKINSHAW M.D.: Structures of immunophillins and their ligand complexes. Curr. Top. Med. Chem., 3 (12): 1392-409, 2003.

6- RAMACHANDRAN S. ,VENUGOPAL A., KUTTY V.R., CHITRASREE V., MULLASSARI A., et al.: Plasma level of cyclophilin $\mathrm{A}$ is increased in patients with type 2 diabetes mellitus and suggests presence of vascular disease. Cardiovasc. Diabetol., 13 (7): 13-38, 2014.

7- NIGRO P., POMPILIO G. and CAPOGROSSI M.C. : Cyclophilin A: A key player for human disease. Cell. Death. and Disease, 4: 410, 2013.

8- SUZUKI J., JIN Z.G., MEOLI D.F., MATOBA T. and BERK B.C.: Cyclophilin A is secreted by a vesicular pathway in vascular smooth muscle cells. Circ. Res., 98: $811-7,2006$

9- YAN J., ZANG X., CHEN R., YUANW., GONG J., et al.: The clinical implications of increased cyclophilin A levels in patients with acute coronary syndromes, Clinica. Chimica. Acta., 413: 691-695, 2012.

10- PAL S.N. and KOFIDIS T.: New cell therapies in cardiology. Expert. Rev. cardiovasc. Ther., 10: 1023- 1037, 2012.

11- GOODACRE S., LOCKER T., MORRIS F. and CAMPBELL S.: How useful are clinical features in the diagnosis of acute, undifferentiated chest pain. Acad. Emerg. Med., 9: 203-8, 2002.

12- LIOYD-JONES D., ADAMS R., BROWN T.M., CARNETHON M., DAI S., et al.: American Heart association statistics committee and stroke statistics subcommittee. Circulation., 119 (3): 480-486, 2009.

13- CHRISTENSON R.H., VAIDYA H. and LANDT Y. Standardization of creatine kinase (CK-MB) mass assays: The use of recombinant CK-MB as a reference material. Clin. Chem., 45: 1414-1423, 1999.

14- RAMACHANDRAN S., VENUGOPAL A., SATHISHA K., RESHMI G., CARLES S., et al.: Proteomic profiling of high glucose primed monocytes identifies cyclophilin A as a potential secretory marker of inflammation in type 2 diabetes. Proteomics, 12: 2808-2821, 2012. 
15- SEIZER P., UNGERN-STERNBERG S.N., SCHÖNBERGER T., BORST O., MÜNZER P., et al.: Cyclophilin $A$ and EMMPRIN (CD147) in cardio vascular diseases. Cardio. Vascular. Reasearch, 102: 17-23, 2014.

16- JIN Z.G., LUNGU A.O., XIE L., WANG M., WONG C. and BERK B.C.: Cyclophilin A is a proinflammatory cytokine that activates endothelial cells. Arterioscler. Thromb. Vasc. Biol., 24: 1186-91, 2004.

17- SATOH K., NIGRO P., MATOBA T., O'DELL M.R., CUI Z., et al.: Cyclophilin A enhances vascular oxidative stress and the development of angiotensin II-induced aortic aneurysms. Nat. Med., 15: 649-56, 2009.

18- ROSSOUW J.E, ANDERSON G.L and PRENTICE R.L.: Writing Group for the women's Health Initiative investigations . Risk and benefits of estrogen plus progestin in healthy postmenopausal women: Principal results from the women's Health Initiative Randomized Controlled Trial. JAMA, 288: 321-333, 2002.

19- TOWFIGHI A., ZHENG L. and OVBIAGELE B.: Sexspecific trends in mid life coronary heart disease risk and prevalence. Arch. Intern. Med., 169: 1762-1766, 2009.

20- MICHELLE BADASH M.S.: Conditions in Depth: Coronary Artery Disease (CAD) and Angina. In: Heart disease: A textbook of cardiovascular medicine. WB Saunders, 8 90-905, 2001.

21- FUSEGAMA Y., GOTO S. and HANDA S.: Platelet spontaneous aggregation in platelet-rish plasma is increased in habitual smokers. Thromb. Res., 93-271, 1999.

22- BOYLE P.J.: Diabetes mellitus and macrovascular disease: Mechanisms and mediators. Am. J. Med., 120: S12-S17, 2007

23- STEPHEN, MURAT TUZCU E. and SRINIVASE K.: Effects of Diabetes on progression of coronary Atherosclerosis and Arterial pimodeling: A pooled Analysis of 5 Intravascular Ultrasound trials Original Research Article. J. Am. Coll. Cardio., 52 (4): 255 -262, 2008.

24- FOLY R.N., HERZOG C.A. and COLLINS A.J.: United States Renal Data System. Blood pressure and long-term mortality in United States hemodialysis patients. Kidney. Int., 62: 1784-1790, 2002.

25- ASSMANN G., SCHULTE H., FUNKE H., VON ECKARDSTEIN A. and SEEDORF U.: The prospective cardiovascular munster (PROCAM) study, identification of high- risk individuals for myocardial infarction and the role of HDL in: Miller N.E., ed High-density lipoproteins and atherosclerosisII . Amsterdam Elserver Science Publishers, 51-65, 2003.

26- GORDON D.J., PROBSTFIELD J.L. and GARRISON R.J.: High density lipoprotein cholesterol and cardiovascular disease: For prospective American studies. Circulation, 112: 433-37, 1999.

27- DENG Y.Z., FENG Z.C. and DIA G.Z.: Serum Apo A-I, apo A-II nts with CHD and their clinical significance. Acta. Acad. Med. Jongji. (Wuhan), 4- 237, 2002.

28- RYOKO M., SHIN-ICHIRO M. and BO ZHANG: HDLassociated factors provide additional prognostic information for coronary artery disease as determined by multi- detector row computed tomography. International Journal of Cardiology, 143 (1): 72-78, 2010.

29- RIDKER P.M., HENNEKENS C.H. and BURING J.E.: C-reacttive protein and other markers of inflammation in the prediction of cardiovascular disease in women. $\mathrm{N}$. Engl. J. Med., 342: 836-43, 2000.

30- JAHN J., HELLMANN I., MAASS M., GIANNITSIS E., DALHOFF K., et al.: Time-dependent changes of hs-CRP serum concentration in patients with non-ST elevation acute coronary syndrome. Herz., 29: 795-801, 2004.

31- BRUNETTI N.D., TROCCOLI R., CORREALE M., PELLEGRINO P.L. and DI BIASE M.: C-reactive protein in patients with acute coronary syndrome: Correlation with diagnosis, myocardial damage, ejection fraction and angiographic findings. Int. J. Cardiol., 109: 248-56, 2006.

32- KIM H., YANG D.H. and PARK Y.: Incremental prognostic value of $\mathrm{C}$-reactive protein and $\mathrm{N}$-terminal proB -type natriuretic peptide in acute coronary syndrome. Circ. J. 70: 1379-84, 2006.

33- BRAUNWALD E., ANTMAN E.M., BEASLEY J.W., CALIFF R.M., CHEITLIN M.D., et al.: ACC/AHA guidelines for the management of patients with unstable angina and non-ST-segment elevation myocardial infarction. A report of the American College of Cardiology/American Heart Association Task Force on Practice Guidelines (Committee on the Management of Patients With Unstable Angina. J. Am. Coll. Cardiol., 36: 970-1062, 2000.

34- KARRAS D.J. and KANE D.L.: Serum markers in the emergency department diagnosis of acute myocardial infarction. Emerg. Med. Clin. North. Am., 19: 321-37, 2001.

35- SATOH K., NIGRO P., ZEIDAN A., SOE N.N., JAFFRE F., et al.: Cyclophilin A promotes cardiac hypertrophy in apolipoprotein E-deficient mice. Arterioscler. Thromb. Vasc. Biol., 31: 1116-1123, 2011.

36- SATOH K., NIGRO P. and BERK B.C.: Oxidative stress and vascular smooth muscle cell growth: A mechanistic linkage by cyclophilin A. Antioxid. Redox. Signal., 12: 675-682, 2010.

37- JIN Z.G., MELARAGNO M.G., LIAO D.F., YAN C., HAENDELER J., et al.: Cyclophilin A is asecreted growth factor induced by oxidative stress. Circ. Res., 87: 789796,2000

38- NIGRO P., POMPILIO G. and CAPOGROSSI M.C.: Cyclophilin A: A key player for human disease. Cell. Death and Disease, 4: 410, 2013.

39- SATOH K.: Cyclophilin A in Cardiovascular Homeostasis and Diseases.Tohoku. J. Exp. Med., 235: 1-15, 2015.

40- SATOH K., FUKUMOTO Y. and SUGIMURA K.: Plasma cyclophilin A is a novel biomarker for coronary artery disease. Circ. J., 77: 447-455, 2013.

41- RAMACHANDRAN S. and KARTHA C.C.: CyclophilinA: A potential screening marker for vascular disease in type-2 diabetes. Can. J. Physiol. Pharmacol., 90: 1005$15,2012$.

42- WEINTRAUB N.L.: Understanding abdominal aortic aneurysm. N. Engl. J. Med., 361: 1114-1116, 2009. 
43- YAN J., ZANG X., CHEN R., YUANW, GONG J., et al.: The clinical implications of increased cyclophilin A levels in patients with acute coronary syndromes, Clinica. Chimica. Acta., 413: 691-695, 2012.
44- SEIZER P., UNGERN-STERNBERG S.N., SCHÖNBERGER T., BORST O., MÜNZER P., et al.: Cyclophilin A and EMMPRIN (CD147) in cardio vascular diseases. Cardio. Vascular. Reasearch, 102: 17-23, 2014.

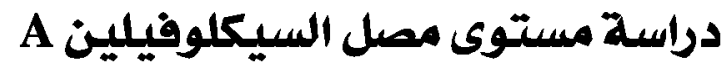

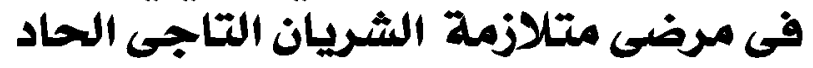

يعرف سيكلوفيلينA أيضاً بعامل النمو ويعمل من خلال مستقبلات ويحفز بسبب الاكسدة التى تعمل كوسيط لتلف الأنسجة المصاحب لالإلتهاب والأكسدة.

تؤكد طبيعة إفراز هذا البروتين ووجوده فى مصل المرضى الذين يعانف من متلازمة الشريان التاجى الحاد قدرته كدلالة للمرض.

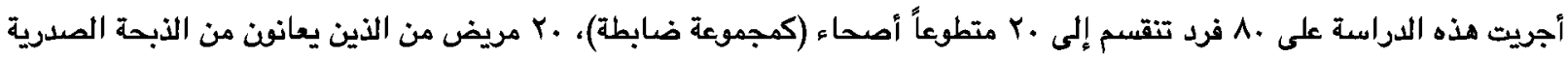

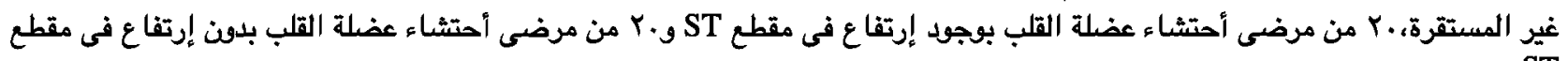

قد خلصت الدراسة إلى مستوى السيكوفيلينA متزايد فى مرضى الشريان التاجى الحاد مما يشير إلى دود هذا البروتين فى إسراع عملية تصلب الشرايين فى مرضى الشريان التاجى الحاد و دوره كوسيط فى تصلب الثرئي الثرايين. 